\title{
An Intertextual Approach to Translation at the Micro-Level
}

\author{
Honghui Zhao \\ School of English and Education, Guangdong University of Foreign Studies, Guangzhou, China \\ Email:vanessazhao@126.com
}

How to cite this paper: Zhao, H.H. (2017) An Intertextual Approach to Translation at the Micro-Level. Open Journal of Social Sciences, 5, 119-127.

https://doi.org/10.4236/jss.2017.511009

Received: November 3, 2017

Accepted: November 25, 2017

Published: November 28, 2017

Copyright $\odot 2017$ by author and Scientific Research Publishing Inc. This work is licensed under the Creative Commons Attribution International License (CC BY 4.0).

http://creativecommons.org/licenses/by/4.0/

\begin{abstract}
In current work on semiotic theory, Kristeva is the first to use the concept of intertextuality to refer to the existence of prior discourse as a precondition for the act of signifying, almost regardless of the semantic context of a given text. Introducing the notion of intertextuality into translation studies is of vital importance. In many cases, the connotative meaning and the overall intention of the author is detected in the process of referring to other closely related texts. Only when the translator is appreciative of such intertextual inferences can he/she fully understand the intended meaning of a given text and then produce a good translated version. This paper discusses the influence of intertextuality on translation at the micro-level by analyzing some intertextual references in literary works and proposes several translation strategies.
\end{abstract}

\section{Keywords}

Intertextuality, Translation Strategy, Micro-Level

\section{A Brief Introduction to the Concept of Intertextuality}

\subsection{Origin of Intertextuality}

The term intertextuality was coined by Julia Kristiva, the French semioticist. She defined it as the relationships between one text and other texts. Any text is constructed as a mosaic of quotations and any text is the absorption and transformation of another [1]. Kristeva used the concept to refer to the existence of prior discourse as a precondition for the act of signifying, almost regardless of the semantic content of a given text. It is actually a combination of the theories of Saussure and Bakhtin. Kristeva reexamines the relational nature of meaning and texts by taking into account the synchronic or diachronic social, cultural and literary contexts and by emphasizing the role of the author in adapting the 
pre-existent materials to his own purposes. Kristeva's work occurred during a transitional period in modern literary and cultural theory, which is often described as a move from structuralism to post structuralism. "It is characterized as one in which assertions of objectivity, scientific rigor, methodological stability and other highly rationalistic-sounding terms are replaced by an emphasis on uncertainty, indeterminacy, incommunicability, subjectivity, pleasure and play" [2].

As a breakthrough of the traditional literary theory, intertextuality has taken up by practically every theoretical movement. What impacts will it have on translation study and how will translators cope with it? These are the problems that this paper attempts to explore.

\subsection{Enlightenment of Intertextuality to Translation}

Intertextuality is employed to challenge the long-held traditional assumptions concerning the role of the author in the production of meaning and the very nature of literary meaning itself. It is a departure from the isolated text theory in the structuralism tradition and is very useful in detecting the subtle meaning of a concrete element in a text in a micro sense and the interaction and aim of a text as a whole. It is evident that intertextuality enlightens practical pursuits such as translating and interpreting. In many cases, the connotative meaning and the overall intention of the author is detected in the process of referring to other closely related texts. More importantly, intertextual theory holds that readers as well as critics participate in the complement of the works, and the author is no longer the creator. He only acts as a role that provides an area of space for the interplay between texts. Thus, creativity and productivity are transferred from the author to the text or the interplay between texts.

Intertextuality provides a special approach for translation studies. Without knowledge of intertextual theory and practice, translators are likely to retain traditional notions of writing and reading, which have been radically challenged. This paper discusses the influence of intertextuality on translation at the micro-level by analyzing intertextual references in the ST and proposes several translation strategies in literary works.

\section{Classifications of Intertextuality}

Intertextuality is a very broad notion which can operate at any level of text organization, and its expression ranges from single words or phrases that have significance in a given text, to macro-textual conventions and constraints associated with genre, register and discourse. That the concept of intertextuality can be understood in various ways points to the need for classifications. In order to outline the notion, scholars have attempted to classify different types of intertextuality. They are summarized and expanded upon as follows:

\subsection{Intratextuality vs. Extratextuality}

This distinction is made by Lemke in 1985. The relationships that exist between 
elements of a given text are called intratexuality. And those existing between distinct texts are extratextuality.

\subsection{Contratextuality}

Speakers or writers may refer to a different text with their own purpose, which may be contrary to those of that text. The intertextual relationship in this case is called contratextuality. For instance, in his famous novel Ulysses, Joyce imitated various styles of previous writers to produce a funny effect.

\subsection{Horizontal Intertextuality vs. Vertical Intertextuality}

According to Kristeva, horizontal intersexuality can be defined as the simultaneous orientation toward the writing subject and the receiver while vertical intertextuality refers to the simultaneous orientation of the discourse toward the literary tradition and the present situation. Applying the concepts introduced by Kristeva and citing the work of Bakhtin, Hatim continues to distinguish between these two concepts. In horizontal intertexuality the relation between two texts is explicit, that is, a text, or extract thereof, written in reply to or development of another one, for example. In contrast, vertical intertextuality is more implicit, and may relate to writing conventions [3].

\subsection{Passive Intertextuality vs. Active Intertextuality}

If an intertextual link activates knowledge and belief systems well beyond the text itself, the intertextual relation is called active intertextuality. On the contrary, if the intertextual link is only used to achieve coherence, then the intertexual relation is called passive intertextuality.

\subsection{Manifest Intertextuality vs. Constitutive Intertextuality}

Norman Fairclough introduces a more systematic approach to intertextuality, which is designed to make the basic concept easier to apply. He makes a distinction between manifest intertextuality and constitutive intertextualilty. The former refers to those intertextual references typically expressed through surface textual features such as quotations and citations while the latter is much more opaque. The reference is there in the surface features of the text but the reader has to make an effort to retrieve it [4].

\subsection{Specific Intertextuality vs. Generic Intertextuality}

Hatim also makes a distinction between socio-cultural objects and socio-textual practices as vehicles of intertexual reference. Socio-cultural objects operate at the micro-level and may be conveyed in a single word or phrase that has particular significance for a given culture at a given time. A typical example is the biblical reference to Judas in describing someone as a traitor.

Socio-textual practices are the macro-constraints and conventions governing register, genre, discourse and text type, which make it possible to recognize a 
given text. For example, judged from conventional features such as the absence of auxiliary verbs and definers, "Star-studded 'Murder on the Orient Express' on its Way" is recognizable as a newspaper headline.

Illuminated by this dichotomy and viewing from the angle of the reader, Xin Bin (2000) subdivides intertextuality into two types: specific intertextuality and generic intertextuality. The former is related to the text including an element or elements with specific source(s) from pre-texts, while the latter deals with the blending of different style, register and genre in a given text [5].

Clearly, these above-mentioned types of classification are overlapping to some extent. As intertextuality can be discussed at different levels, to avoid confusion, we will probe into literary translation studies from an intertextual approach at the micro-level based on the dichotomy made by Xin Bin as mentioned above: micro-level (specific intertextuality) and macro-level (generic intertextuality). To put it more clearly, the former type mainly deals with intertextuality at the lexical and syntactic level while the latter intertextuality at the textual level.

By intertextuality at the micro-level, we will discuss the adjustments the translator has to make in dealing with specific intertextual references in the ST at the lexical and syntactic level. Neglecting, ignoring or misjudging the context in which an intertextual reference is applied will lead to mistranslations. Therefore, how to spot out intertextual references in the ST and what adjustments a translator has to make is of vital significance in translating.

\section{An Intertextual Approach to Translation at the Micro-Level}

\subsection{Analysis of Intertextual References in Literary Works}

Intertextuality is basically a semiotic mechanism through which texts are recognized in terms of their dependence on other relevant texts. By intertextuality a text refers to previous or future texts, by alluding to, adopting, or invoking meanings expressed in those other texts. Translators should be able to recognize and understand such intertextual references so that they can fully transfer the intended meaning in a given text. Otherwise, it will result in partial understanding or misunderstanding of the intended meaning of the text concerned [6].

Intertextual references are said to belong to one of the following categories: reference, cliché, literary allusion, citing or referring to a celebrated work, self-quotation, conventionalism, proverb, and mediation [7]. These categories do not, however, give a complete picture. Another classification based on an analysis of intertextual references in literary works is presented as follows with exemplification provided when necessary:

1) Citation. Direct quotation of the exact expressions from a previous text indicated by quotation marks.

2) Allusion and prototype. These refer to expressions or typical stories derived from various literary works like the Bible. The stories may be myths, fairy tales, folk tales, historical stories, religious stories, etc. 
3) Collage. Collage refers to the transformation or even distortion of a previous text and the integration of it into a new one.

4) Parody. Parody refers to the imitation of patterns of speaking or languages style characteristic of a particular context or a specific previous text to produce a satirical effect. For instance, James Joyce is a master in employing parody. In his masterpiece Ulysses, language styles of various writers are imitated to achieve an ironical effect.

5) Untraceable codes. Untraceable codes refer to the cultural conventions existing everywhere without a definite source. They may be applied by the author unconsciously into his work [8].

These categories together with those listed above provide us with a comprehensive system of classifying intertextual references in literary works.

\subsection{Translation Strategies}

Intertextual references are mostly culture-specific. Thus, the translator's bicultural competence is no less important than his/her linguistic competence. How to deal with culture-specific expressions is a matter of individual judgment for the translator, and there are a number of satisfactory solutions available. Baker (2000) proposes several strategies for dealing with culture connotation, which are also applicable for intertextual references: 1) literal translation; 2) cultural substitution; 3) elaboration and explication; 4) omission and 5) transliteration [9].

\subsubsection{Literal Translation}

The connotation of intertextual references usually reflects the cultural psychology and tradition of a nation. Literal translation aims to reproduce both the style and content of the literary work and remain the figures of speech and sentence structures as much as possible.

Literal translation can be applied to deal with intertextual reference. LuoXuanmin (2000) illustrates this in his essay On the Two Versions of the Title of Hongloumeng, from the Perspective of Intertextuality. According to Luo, Yang Xianyi's version A Dream of Red Mansions gives no cause for much criticism in form for the expression “红楼” (hóng lóu) has rich cultural connotation in Chinese. It conjures up in our mind the mansions of the nobility, especially the chambers of girls of wealthy families. In this sense, Yang's version takes intertextuality into consideration.

Another literal translation of 《红楼梦》(hóng lóu mèng) is The Story of the Stone, which is the literal translation of 《石头记》 (shí tou jì), the original title of the same literary work, but Hawkes gives priority to the acceptability of the reader of the target text. In westerners' eyes, “红楼” means nothing more than a red house. Consequently, they may understand "hóng lóu mèng" as "a dream in a read house", which simply conveys a romantic sense. That strays too far from the intention of the writer and weakens the cultural connotation of the work. 
Considered from a wider culturally intertextual perspective, Hawkes's version The Story of the Stone is better. It takes the title of the original draft into consideration, and what is more, The Story of the Stone is comparatively easy to be accepted by westerners. The connotation of stones (or sands) is not only familiar to Chinese people but also to westerners as can be seen in the memorable opening stanza of the English poet, William Blake's poem " Auguries of Innocence”:

To see a world in a Grain of Sand,

And a Heaven in a Wild Flower,

Hold Infinity in the palm of your hand,

And Eternity in an hour.

In conclusion, both David Hawkes and Yang Xianyi attached importance to intertextuality in translating. The former dealt with it from a linguistic approach, while the latter a cultural one [10].

\subsubsection{Cultural Substitution}

Cultural substitution means replacing a culture-specific expression with a target-language one that is likely to have a similar effect on the target reader. The benefit of this strategy is that it gives the reader a concept with which s/he can accept easily, something familiar.

The English allusion "a dog in the manger" is roughly equivalent to the Chinese idiom “占着茅坑不拉屎” (zhàn zhe máo kēng bù lā shǐ). Both are used to refer to a person who prevents others from enjoying something that is useless to himself though the latter sounds more or less vulgar. Still another example is the Chinese idiom “柕鸟蚌相争, 渔翁得利” (yù bang xiāng zhēng, yú wēng dé lì) originated from a fable, which roughly means when the snipe and the clam grapple, the fisherman profits-it is the third party that benefits the tussle. When translated literally, this idiom could hardly be acceptable to westerners as there is a lack of such images related to the two animals in western culture. But we can find some equivalent idioms in English like "When shepherds quarrel, the wolf has a winning game" and "Two dogs strive for a bone and a third runs away with it."

However, since the habits, customs and traditions are quite different, the exact equivalence in the target language for each rhetorical device in the source language is not so easy to find, especially such rhetorical devices as chiasmus, pun, etc. In such cases, we can only use other rhetorical devices to substitute them or give a literal translation with a footnote. It is also worthwhile to mention that cultural misreading may lead to mistranslation, which also results from cultural differences. A translator may substitute an item in SL with one in TL which he/she believes equivalent but which actually implies different cultural connotation. This will distort the original writer's intention and mislead TL readers. Take the sentence "He is another Shylock" for example. As Shylock means someone who is not only mean but also merciless, it is inappropriate to substitute “铁公鸡” (tiě gōng jī) for it in E-C translating. 


\subsubsection{Elaboration and Explication}

This is a useful option for the word which lacks an equivalent in the target language. This strategy is particularly common in dealing with culture-specific items in Chinese poems. Sometimes the intertextual references have obtained a relatively fixed connotative meaning and been established as a symbol. In this case, ordinary readers will find them incomprehensible unless there are some explanations followed, so it is necessary for the translator to convey the original meaning and he/she has no choice but to borrow the original item with elaboration and explication supplied by the text or in a footnote. For example, in ancient Chinese poems “凭栏” (píng lán) or “倚栏” (y̌̃ lán) are intertextual referents of high frequency, which literally mean "to lean on railings" or "to loll against the pillars". However, they are widely used to express a strong emotion of the poet, which is often related to some pent-up feelings resulted from a deep concern about one's country or one's people or simply from lovesickness. Since there is no equivalent in the translation, a footnote explaining this code becomes a necessity. A literal translation of it will only lead to some culture loss, which would make the translation fall rather flat in English.

In his translated version of hóng lóu mèng ( $A$ Dream of Red Mansions, Chapter 34), Yang Xianyi wisely translated “东施效蘋” (dōng shī xiào pín) as "Tung Shih imitating Hsi Shih" with a footnote given below: "Hsi Shih was a famous beauty in the late Spring and Autumn Period in ancient China. Tung Shih was an ugly girl who tried to imitate her ways" [11], as an ordinary foreign reader can hardly understand what "Tung Shih" and "Hsi Shih" refer to, let alone the allusion.

\subsubsection{Transliteration}

To keep the cultural information of the SL is both to convey faithfully the information of the SL and to promote the cultural communication between nations. Transliteration with or without annotation is a good strategy by which to keep the cultural information of the intertextual references in the SL. When we use transliteration, we must pay attention to its intelligibility. Otherwise, we will have to give proper footnotes to the transliterations so that the foreign readers may understand them. Though this method is seldom used, it is indispensable. In fact, it has a long history. For example the transliteration of “道” as “Tao" and “德” as “ $T e$ ”, both originated from the Chinese Classical work Tao Te Ching (《道德经》), have already been deep-rooted in English culture. The earliest proof dates back to the year of 1736 in Oxford English Dictionary (vol.17) in which the borrowed word " $\mathrm{TaO}$ " is defined as: "Among the sentences [of Lao Kium] there is one that is often repeated...: Tao, says he, or Reason, have produced one, one have produced two, two have produced three, and three have produced all things" [12]. Similar definitions can be found in other English dictionaries. Look at the transliteration of “阴” and “阳” originated from I CHING or Book of Changes (《周易》) as Yin and Yang. To make it more intelligible, a footnote can be supplied: Yin and Yang represent the two opposite but non-antagonistic and 
mutually transformable sides in human society and nature.

There is no doubt that a lack of intertextual knowledge would lead to misunderstanding of the ST and then an inappropriate translation. Take $\mathrm{Xu}$ Zhongjie's translation of the well-known poem 枫桥夜泊(fēng qiáo yè bó) for example.

Outside the city of Suzhou

Is resounding a distant knell,

It is Cold-Hill Monastery-

Towards us, tolling is midnight bell [13].

The atmosphere described in ST misled Xu to put “寒山” (hán shān) into "Cold Hill". However, there does not exist a cold hill out of Suzhou. In fact, the monastery was named after a monk who lived there in the Tang dynasty. With a knowledge of the intertextual reference here, we can simply translate “寒山寺” (hán shān sì) as "Hanshan Temple/Monastery".

\subsubsection{Translation by Omission}

It may sound drastic, but sometimes it is actually harmless to omit translating a word or expression in a given text. If the meaning conveyed by a particular item or expression is not important and it is unnecessary to distribute the reader with lengthy explanations, translators can simply omit translating the word or expressions in question. Needless to say, there is some culture loss of meaning when words and expressions are omitted in a translation. Therefore, this strategy is recommended to be used only as a last resort, when the advantages of producing a readable translation outweigh the necessity of rendering a particular meaning accurately in a given context.

There is no one single translation strategy for intertextual references in literary texts because there are different sub-branches within them. Translators need to take different strategies to cope with different reference types.

\section{Conclusions}

Intertextuality will remain a crucial element in the attempt to understand literature and culture in general. It is well said that in the Chinese classic: “文承秦汉” (wén chéng qín hàn) (Any Chinese writing may be regarded as originated from those in the Qin or Han Dynasties). A knowledge of intertextualtiy is of great significance in translating a piece of literary writing, for each piece, no matter a new poem or a new novel may be somewhat intertextual with an old one or more than one old ones. In order to create a target text that meets the expectations of the target society, a translator should be able to correctly identify intertextual references in the SL and adopt adequate strategies to deal with them in the TL.

As Intertextuality can be discussed at different levels, it may cause confusion. This paper mainly focuses on intertextuality at the micro-level, i.e. intertextuality at the lexical and syntactic level. More explorations can be made on translation and intertextuality at the macro (or textual) level. 


\section{References}

[1] Kristeva, J. (1980) Desire in Language: A Semiotic Approach to Literature and Art. Columbia University Press, New York.

[2] Allen, G. (2000) Intertextuality. Routledge, New York.

[3] Hatim, B. (1997) "Intertextual Intrusions: Towards a Framework for Harnessing the Power of the Absent Text in Translation. In: Simms, K., Ed., Translating Sensitive Texts. Linguistic Aspects, Rodopi, Amsterdam, 29-46.

[4] Fairclough, N. (1992) Discourse and Text: Linguistic Intertextual Analysis within Discourse Analysis. Discourse and Society, 3, 193-217.

https://doi.org/10.1177/0957926592003002004

[5] Xin, B. (2000) On a Pragmatic Approach to Intertextuality. Foreign Languages Research, 3, 14-16.

[6] Ennis, T. (n.d.) MA Translation Studies-Translation and Discourse. 1-12. https://www.birmingham.ac.uk/Documents/college-artslaw/cels/essays/translationd iscourse/ennis3.pdf

[7] Hatim, B. and Mason, I. (2001) Discourse and the Translator. Shanghai Foreign Language Education Press, Shanghai.

[8] Chen, X.L. (1996) A Survey of Intertextuality Theory. Foreign Literature, 1, 72-78.

[9] Baker, M. (1998) In Other Words: A Course Book on Translation. Routledge, London and New York.

[10] Xie, T.Z. (2000) Theoretical Construction of Translation from a Cultural Perspective. Shanghai Foreign Language Education Press, Shanghai, 174-175.

[11] Yang, X.Y. and Yang, G. (1994) A Dream of Red Mansions. Foreign Languages Press, Beijing.

[12] Wang, R.P. (1997) Comparison and Translation. Shanghai Foreign Language Education Press, Shanghai.

[13] Xu, Z.J. (1990) 200 Chinese Tang Poems in English Verse. Beijing Language Institute Press, Beijing. 